\title{
The influence of steroid receptor status on the cardiotoxicity risk in HER2-positive breast cancer patients receiving trastuzumab
}

\author{
Joanna Huszno, Agnieszka Badora, Elżbieta Nowara
}

Clinical and Experimental Oncology Department, Maria Skłodowska-Curie Memorial Cancer Center and Institute of Oncology, Gliwice Branch, Gliwice, Poland

Submitted: 6 January 2013

Accepted: 21 March 2013

Arch Med Sci 2015; 11, 2: 371-377

DOI: $10.5114 /$ aoms.2015.50969

Copyright $\odot 2015$ Termedia \& Banach

\section{Abstract}

Introduction: Expression of steroid receptors and HER2 overexpression in breast cancer cells are predictive and prognostic factors. Overexpression of HER2 allows the use of immunotherapy, in which the most serious side effect is cardiotoxicity. The aim of this study was to evaluate the influence of steroid receptor status on cardiotoxicity risk in HER2 breast cancer patients receiving trastuzumab both in adjuvant treatment and in the case of disease dissemination. This study also assessed well-known cardiac risk factors.

Material and methods: The study was conducted on 166 patients who received immunotherapy in the Clinical and Experimental Oncology Department, between the years 2006 and 2012 .

Results: A predisposition to cardiac side effects ( $13 \%$ vs. $5 \%$ ) in patients with negative steroid receptor status was observed $(p=0.08)$. The decrease of left ventricular ejection fraction (LVEF) (12\% vs. 0) and cardiac adverse side effects ( $2 \%$ vs. 0 ) were detected only in ER-/PR- patients but without statistical significance. Discontinuation of therapy because of cardiotoxicity was associated with negative receptor status (33\% vs. $7 \%)(p=0.019)$. Irrespective of steroid receptor status, older age of patients $(p=0.009)$ and previous radiotherapy to the left side of the chest $(p=0.02)$ were associated with the occurrence of cardiotoxicity and decrease of LVEF. In patients who received previous anthracycline-based chemotherapy, acute cardiac side effects were observed significantly more often $(p=0.01)$.

Conclusions: There was no influence of steroid receptor status on the cardiac side effects. Breast cancer type containing Erb-B2 overexpression was associated with predisposition to cardiotoxicity. The results require confirmation in a larger group of patients.

Key words: breast cancer, trastuzumab, steroid receptors, cardiotoxicity, risk factors.

\section{Introduction}

The expression of steroid receptors (estrogen and progesterone) and overexpression of HER2 (epidermal growth factor receptor) in breast cancer cells are predictive and prognostic factors. Their status allows one to choose an appropriate treatment strategy (hormone therapy or immunotherapy) and predict therapy response. HER2 overexpression is characteristic for $20-30 \%$ of breast cancer cases and is associated with worse

\author{
Corresponding author: \\ Joanna Huszno MD \\ Clinical and Experimental \\ Oncology Department \\ Maria Skłodowska-Curie \\ Memorial Cancer Center \\ and Institute of Oncology \\ 15 Wybrzeże Armii Krajowej St \\ 44-101 Gliwice, Poland \\ Phone: 660726068 \\ E-mail: joahus@wp.pl
}


prognosis and with a worse chemotherapy and hormone therapy response $[1,2]$. The presence of estrogen receptors (ERs) is observed in $50-70 \%$ of breast cancers [3]. Additionally, 50\% of ER+ tumors also have positive progesterone receptor (PR) status [4]. Estrogen receptors are involved in the regulation of transcription of the gene encoding the PR in the breast. Therefore, the expression of progesterone receptor provides indirect estrogen receptor activation [5].

In about $10 \%$ of cases ER expression is associated with HER2 overexpression, and about $50 \%$ of tumors with HER2 overexpression show at the same time the presence of positive ER receptors $[6,7]$.

The protective activity of estrogens on the cardiovascular system arises from their influence on changes in the plasma lipid level and on expression of pro-inflammatory factors. The beneficial influence of estrogens on the tension of blood vessel walls and their antioxidative action is also known [8].

Two mechanisms of estrogen activity are distinguished: genomic, which is associated with receptor activation, and a non-genomic mechanism (immediate) without receptor involvement. The non-genomic mechanism of estrogen activity is associated with the stimulation of nitric oxide and with a direct effect on L-type calcium channels and potassium channels.

Estrogen receptors belong to the nuclear receptors which regulate transcription. Estrogens enter the cell by diffusion and then bind to the intracellular receptor. The estrogen receptor changes its conformation, and that enables it to attach to specific DNA sequences - estrogen response elements (EREs). There are two main proteins with properties of estrogen steroid receptors: ER $\alpha$ and $E R \beta$. The connection of ER $\alpha$ with estradiol causes activation of transcription and with ER $\beta$ its inhibition [9]. Both of them appear in variable proportions in different tissues such as heart and blood vessels [10]. The presence of active estrogen receptors in myocardium regulates in a non-genomic mechanism expression of genes which encode connexin 43 and heavy chains of myosin. They are one of the most important proteins responsible for contractility of myocardium [11].

The genes encoding estrogen receptors are polymorphic, and their variability may affect the level of protein biosynthesis. Polymorphisms of both steroid receptors have been associated with predisposition to cardiovascular disease: ER $\alpha$ with risk of coronary artery disease [12] and ER $\beta$ with left ventricular wall thickness in women with hypertension and with blood pressure in men [13].

Nowadays, HER2-positive breast cancer patients receive trastuzumab - a human monoclonal antibody, selectively targeted at the extracellular domain of the human epidermal growth factor 2 [14]. The commonest side effect of trastuzumab treatment is cardiotoxicity, which manifests as heart failure with a decrease of the left ventricular ejection fraction (LVEF) or only as a significant, asymptomatic decrease of LVEF [15]. The rate of heart failure during trastuzumab treatment is assessed at about $4-7 \%$, of which about 3\% applies to grade 3-4 toxicity according to the Common Terminology Criteria for Adverse Events (CTCAE) classification [16].

Up to now, the influence of breast cancer subtype on the cardiotoxicity risk has not been estimated and the steroid receptor status is not an approved risk factor. The aim of this study was to evaluate the influence of steroid receptor status (ER/PR) profile on cardiotoxicity risk in HER2 breast cancer patients receiving trastuzumab both in adjuvant treatment and in case of disease dissemination. In this study the influence of well-known cardiovascular risk factors was also assessed.

\section{Material and methods}

The retrospective study was conducted on a group of 166 women treated in the Clinical and Experimental Oncology Department of the Oncology Centre - Maria Sklodowska-Curie Memorial Institute (Gliwice Branch), between the years 2006 and 2012. The study group comprised breast cancer patients with HER2 receptor overexpression or HER2 gene amplification. HER2 overexpression was assessed using an immunohistochemical method (IHM) in postoperative specimens or in samples obtained by thick needle biopsy. HER2 gene amplification was additionally assessed by fluorescence in situ hybridization (FISH) in 16\% of patients. Inclusion criteria were: baseline LVEF $>50 \%$ and medical history without major pathologies such as unstable ischemic heart disease, valvular heart disease, chronic hypertension with cardiovascular problems or uncontrolled diabetes (uncontrolled diabetes was classified as a random blood glucose level $\geq 11.0 \mathrm{mmol} / \mathrm{l}$ in diabetic patients). Patients' characteristics and treatment strategies are shown in Tables I and II. Performance status was evaluated by the Zubrod classification (from 0 to 5 , with 0 denoting perfect health and 5 death). Trastuzumab was used in adjuvant therapy in 108 (65\%) patients and in the remaining 58 (35\%) for the treatment of metastatic disease. Steroid receptor status (ER/PR) was evaluated by an immunohistochemical method on a semi-quantitative scale. Steroid receptor status and breast cancer subtypes are presented in Table III.

Adjuvant therapy consisted of 18 infusions of trastuzumab. Patients treated for metastatic disease received between 2 and 118 infusions (median number: 23). Estimation of treatment effect 
Table I. Patients' characteristics

\begin{tabular}{|c|c|c|}
\hline Parameter & $\begin{array}{c}\text { Number of } \\
\text { patients }\end{array}$ & $\begin{array}{c}\text { Percent of } \\
\text { patients }\end{array}$ \\
\hline \multicolumn{3}{|c|}{ Age median 54 years; mean 53 years: } \\
\hline$<50$ & 52 & 31 \\
\hline$>50$ & 114 & 69 \\
\hline \multicolumn{3}{|l|}{$\begin{array}{l}\text { Performance status } \\
\text { (Zubrod): }\end{array}$} \\
\hline 0 & 94 & 57 \\
\hline$\geq 1$ & 72 & 43 \\
\hline \multicolumn{3}{|l|}{ Smoking history: } \\
\hline Yes & 65 & 39 \\
\hline No & 101 & 61 \\
\hline \multicolumn{3}{|l|}{ Family history: } \\
\hline Diabetes & 6 & 4 \\
\hline Hypertension & 37 & 23 \\
\hline $\mathrm{BMI}>25 \mathrm{~kg} / \mathrm{m}^{2}$ & 85 & 51 \\
\hline \multicolumn{3}{|l|}{ Histological type: } \\
\hline Ca ductale invasivum & 135 & 81 \\
\hline Ca lobulare invasivum & 4 & 2 \\
\hline Others & 27 & 17 \\
\hline \multicolumn{3}{|l|}{ BMI: } \\
\hline Norm & 73 & 44 \\
\hline Overweight & 64 & 39 \\
\hline Obesity & 29 & 18 \\
\hline \multicolumn{3}{|l|}{ Hypertension: } \\
\hline Yes & 37 & 22 \\
\hline No & 129 & 78 \\
\hline \multicolumn{3}{|l|}{ Diabetes: } \\
\hline Yes & 6 & 4 \\
\hline No & 160 & 96 \\
\hline
\end{tabular}

was carried out every 3 cycles. Echocardiography was performed every 3 months during trastuzumab therapy and also before and after the anthracyclines. Cardiac side effects were assessed using the NYHA (New York Heart Association) classification and the CTCAE scale (ver. 4.0) (Table IV). The earliest manifestations of myocardial damage diagnosed by echocardiography were LVEF decrease, abnormalities of right ventricular contractility, ventricular dilation and abnormalities of left ventricular contractility.

We analyzed the dependence between steroid receptor status - ER(+)/PR(+)/HER(+), ER(+)/PR(-)/
Table II. Patients' treatment

\begin{tabular}{|c|c|c|}
\hline Parameter & $\begin{array}{c}\text { Number of } \\
\text { patients }\end{array}$ & $\begin{array}{c}\text { Percent of } \\
\text { patients }\end{array}$ \\
\hline \multicolumn{3}{|l|}{ Surgery: } \\
\hline Yes & 139 & 84 \\
\hline No & 27 & 16 \\
\hline \multicolumn{3}{|l|}{ Radiotherapy: } \\
\hline Yes & 123 & 74 \\
\hline No & 43 & 26 \\
\hline \multicolumn{3}{|l|}{ Hormone therapy: } \\
\hline Yes & 99 & 60 \\
\hline No & 67 & 40 \\
\hline \multicolumn{3}{|c|}{ Anthracycline-based chemotherapy: } \\
\hline Yes & 130 & 78 \\
\hline No & 12 & 7 \\
\hline \multicolumn{3}{|l|}{ Immunotherapy: } \\
\hline Adjuvant therapy & 108 & 65 \\
\hline Metastatic disease & 58 & 35 \\
\hline
\end{tabular}

Table III. Steroid receptor status and breast cancer subtypes

\begin{tabular}{|c|c|c|}
\hline Parameter & $\begin{array}{c}\text { Number of } \\
\text { patients }\end{array}$ & $\begin{array}{c}\text { Percent of } \\
\text { patients }\end{array}$ \\
\hline \multicolumn{3}{|c|}{ Estrogen receptor status (ER): } \\
\hline Positive & 96 & 57 \\
\hline $\mathrm{ER}+$ & 35 & 21 \\
\hline $\mathrm{ER++}$ & 34 & 20 \\
\hline $\mathrm{ER}+++$ & 27 & 16 \\
\hline Negative & 70 & 43 \\
\hline \multicolumn{3}{|c|}{ Progesterone receptor status (PR): } \\
\hline Positive & 82 & 49 \\
\hline $\mathrm{PR}+$ & 42 & 25 \\
\hline $\mathrm{PR}++$ & 24 & 14 \\
\hline $\mathrm{PR}+++$ & 16 & 10 \\
\hline Negative & 84 & 51 \\
\hline $\mathrm{ER}(+) / \mathrm{PR}(+) / \mathrm{HER}(+)$ & 77 & 46 \\
\hline $\mathrm{ER}(+) / \mathrm{PR}(-) / \mathrm{HER}(+)$ & 18 & 11 \\
\hline $\mathrm{ER}(-) / \mathrm{PR}(+) / \mathrm{HER}(+)$ & 7 & 4 \\
\hline $\mathrm{ER}(-) / \mathrm{PR}(-) / \mathrm{HER}(+)$ & 64 & 39 \\
\hline HER ++ (amplification) & 16 & 10 \\
\hline HER+++ & 150 & 90 \\
\hline
\end{tabular}


Table IV. CTCAE criteria (version 4.0)

\begin{tabular}{|lc|}
\hline Criteria & Definition \\
\hline 1 & Asymptomatic, resting ejection fraction $(\mathrm{EF})<60-50 \%$, shortening fraction (SF) $<30-24 \%$ \\
\hline 2 & Asymptomatic, resting ejection fraction $\mathrm{EF}<50-40 \%, \mathrm{SF}<24-15 \%$ \\
\hline 3 & Presence of congestive heart failure symptoms responding to treatment. EF $<40-20 \%, \mathrm{SF}<15 \%$ \\
\hline 4 & Refractory congestive heart failure or poorly controlled. EF $<20 \%$. Unavoidable treatment. \\
\hline 5 & Partial resection of the chamber, heart transplant \\
\hline
\end{tabular}

$\operatorname{HER}(+), \operatorname{ER}(-) / \operatorname{PR}(+) / \mathrm{HER}(+), \operatorname{ER}(-) / \mathrm{PR}(-) / \mathrm{HER}(+)-$ and development of cardiotoxicity due to trastuzumab employment in breast cancer patients. Additionally, we evaluated the influence of other well-known risk factors including age at disease onset, menopausal status, smoking, hormone receptor status, previous chemotherapy containing anthracyclines, previous radiotherapy to the left side of the chest, comorbidities (diabetes, hypertension, obesity) and baseline LVEF on cardiotoxicity development depending on steroid receptor status.

\section{Statistical analysis}

Statistical analysis was performed using Statistica 7 (StatSoft). The influence of steroid receptor status (triple negative, ER+/PR+, ER+/PR-, ER-/PR-, $E R-/ P R+)$ on cardiotoxicity development and treatment response was analyzed by Fisher's test and the $\chi^{2}$ test with Yates correction. The impact of risk factors on the development of cardiac side effects was evaluated by multivariate ANOVA. Statistical inference was based on the $p$ value determined by using a one-tailed test and $95 \%$ confidence intervals.

\section{Results}

During trastuzumab therapy, a total of 59 (36\%) patients had reduced LVEF relative to baseline values. The LVEF reduction observed in the majority of patients was clinically insignificant, not exceeding $10 \%$ of the baseline value. In 10 (6\%) women, the LVEF reduction exceeded $10 \%$ of the baseline. In 5 patients the LVEF decrease did not exceed $15 \%$, and in the remaining 5 it was higher than $15 \%$ of the baseline. Two patients had an accumulation of fluid in the pericardium. Decompensated heart failure manifesting as a considerable limitation of physical activity, heart palpitations and dyspnea developed in 2 patients, while abnormal contractility (generalized hypokinesia) emerged in 5 patients. A full description of LVEF changes during trastuzumab therapy is included in Table $\mathrm{V}$.

The analysis did not demonstrate an association between steroid receptor status and predisposition to cardiac side effects of trastuzumab treatment $(p=0.419)$. There observed tendency to cardiotoxicity development in patients with negative steroid receptor status (ER-/PR-) (13\% vs. $5 \%)(p=0.08$; OR $=0.35)$. There was no difference in the lower initial baseline LVEF (EF about

Table V. Symptomatic and asymptomatic cardiac events

\begin{tabular}{|lccccccc|}
\hline Cardiotoxicity & $\begin{array}{c}\text { NYHA } \\
\text { criteria }\end{array}$ & $\begin{array}{c}\text { No. of } \\
\text { risk } \\
\text { factors }\end{array}$ & $\begin{array}{c}\text { LVEF before } \\
\text { trastuzumab } \\
\text { [\%] }\end{array}$ & $\begin{array}{c}\text { Lowest } \\
\text { LVEF } \\
\text { value [\%] }\end{array}$ & $\begin{array}{c}\text { Time of } \\
\text { occurrence } \\
\text { [cycles] }\end{array}$ & $\begin{array}{c}\text { Trastuzumab } \\
\text { continuation }\end{array}$ & $\begin{array}{c}\text { LVEF after } \\
\text { completion of } \\
\text { therapy [\%] }\end{array}$ \\
\hline Asymptomatic & II & 2 & 52 & 45 & 48 & Yes & 55 \\
\hline Symptomatic & III & 3 & 59 & 39 & 12 & No & 41 \\
\hline Asymptomatic & II & 1 & 55 & 43 & 22 & Yes & 53 \\
\hline Symptomatic & IV & 1 & 58 & 35 & 12 & No & 38 \\
\hline Asymptomatic & II & 2 & 60 & 40 & 8 & No & 45 \\
\hline Asymptomatic & II & 3 & 50 & 35 & 22 & No & 40 \\
\hline Asymptomatic & I & 2 & 56 & 46 & 4 & Yes & 51 \\
\hline Asymptomatic & I & 0 & 58 & 45 & 8 & No & 48 \\
\hline Asymptomatic & I & 1 & 70 & 55 & 18 & Yes & 60 \\
\hline Asymptomatic & I & 1 & 55 & 45 & 6 & Yes & 56 \\
\hline
\end{tabular}


$50 \%)$ in patients with positive and negative receptor status (13\% vs. $9 \%)(p=0.361)$. A decrease of LVEF during immunotherapy was observed only in patients with negative receptor status (12\% vs. $0)$, but without statistical significance $p=0.140$. No differences were detected between disorder of myocardial contractility ( $7 \%$ vs. $4 \%, p=0.440$ ), the presence of fluid in the pericardial sac ( $1 \%$ vs. $1 \%, p=0.896)$ and steroid receptor status. Cardiac adverse side effects (shortness of breath, significant impairment of exercise tolerance, stenocardial disorders) were observed only in the group with negative receptor status ( $2 \%$ vs. 0$)(p=0.191)$. Similarly, there was no influence of positive receptor status on increase of blood pressure (4\% vs. $1 \%)(p=0.229)$. Discontinuation of therapy because of cardiac side effects was associated with negative receptor status ( $33 \%$ vs. $7 \%$ ) ( $p=0.019$; $\mathrm{OR}=6.5)$. The presence of positive progesterone receptor status $(\mathrm{PR}+)$ with negative estrogen receptor (ER-) did not affect the frequency of cardiotoxicity, including acute cardiac side effects in comparison with the patients with positive steroid receptor status (ER+/PR+).

In evaluation of treatment response, complete remission $(C R)$ + partial remission (PR) were observed more often in patients with positive steroid receptor status (65\% vs. $45 \%)(p=0.03 ; \mathrm{OR}=2.27)$. No difference was detected in local recurrence in patients with negative receptor status (72\% vs. $62 \%)(p=0.249)$. In the studied group disease dissemination was observed in the same frequency, regardless of the receptor status (53\% vs. 52\%) $(p=0.898)$.

Multivariate ANOVA showed the influence of risk factors such as age $(p=0.004)$ on decreased rate of cardiac side effects in patients with positive steroid receptor status. The usage of anthracycline-based chemotherapy $(p=0.225)$, previous radiotherapy to the left side of the chest $(p=0.689)$, diabetes $(p=0.445)$, hypertension $(p=$ $0.903)$, and high body mass index BMI ( $p=0.551)$ did not affect cardiotoxicity of the immunotherapy. Irrespective of steroid receptor status, older age of patients $(p=0.009)(\mathrm{OR}=8)$ and previous radiotherapy to the left side of the chest $(p=0.02)$ $(\mathrm{OR}=3.3)$ were associated with the occurrence of cardiotoxicity and decrease of LVEF. In patients who received previous anthracycline-based chemotherapy, significantly more often acute cardiac side effects were observed $(p=0.01)(\mathrm{OR}=0.2)$.

\section{Discussion}

The current study is the first to examine the influence of steroid receptor status on cardiac side effects (cardiac adverse events and LVEF reduction) in a retrospective study of 166 patients with HER2-positive breast cancer receiving treatment with adjuvant chemotherapy and for metastatic disease.

Immunohistochemical indication of estrogen and progesterone receptor status, detection of HER2 oncogene overexpression or amplification (human epidermal growth factor receptor 2) and evaluation of cell proliferation rate (Ki67) allowed us to identify breast cancer subtypes such as luminal A (ER+/PR+/HER2+/low KI67), luminal B HER2 negative (ER+/PR+/HER2-/high K167), luminal B/ HER2 positive (ER+/PR+/HER2+/any KI67), overexpression of Erb-B2 (ER-/PR-/HER2+) and basal like type (ER-/PR-/HER2-) [14]. In the studied group the most common types of breast cancer were: HER2 positive non luminal type (39\%) and luminal B HER2 positive (46\%) (Table III). There was observed tendency to cardiac side effects in the breast cancer type with overexpression of Erb-B2 (ER-/PR-/HER2+) (13\% vs. 5\%; $p=0.08)$. In this type of breast cancer therapy, disruption because of cardiotoxicity ( $33 \%$ vs. $7 \%)(p=0.019)$ was also more often observed.

In the studied group positive receptor status was observed both in older patients and in younger women ( $59 \%$ vs. $45 \%)$ ( $p=0.371)$. According to the literature, tumors with steroid receptor expression are more often observed in older patients, and this can be associated with lower postmenopausal estrogen concentration and with smaller receptor saturation [17]. The results may be due to the nature of the analyzed group. About $13 \%$ of patients were aged under 40 years and others were older. Sixty-nine percent of women were in the postmenopausal period. The protective effect of estrogens on the cardiovascular system is a basis for using hormone replacement therapy (HRT) [18]. Older works such as Grady's meta-analysis from 1992 indicated a significant advantage of estrogen usage in postmenopausal women $-35-50 \%$ decrease of coronary artery disease risk. More recent reports pay attention to increased risk of cardiotoxicity balancing the protective value of estrogens [19].

In the conducted analysis, age $(p=0.004)$ caused an increase of the cardiotoxicity rate in patients with positive receptor status. Previous anthracycline-based chemotherapy $(p=0.01)$ and radiotherapy to the left side of the chest $(p=0.02)$ were, together with patients' age (0.004), cardiotoxicity risk factors, independent of steroid receptor status. Diabetes ( $p=0.445)$, hypertension $(p=0.903)$ and high BMI $(p=0.551)$ did not affect the incidence of cardiac side effects during immunotherapy. Trastuzumab therapy, especially after previous anthracycline-based chemotherapy, has higher risk of cardiotoxicity, which was proved in clinical trials such as HERA (Herceptin Adjuvant Trial), NSABP B31 (National Surgical Adjuvant Breast and Bowel Project), NCCTG N9831 (the 
North Central Cancer Treatment Group), and BCIRG 006 (the Breast Cancer International Research Group) [20, 21]. During trastuzumab monotherapy cardiac side effects appeared in $4-7 \%$ of patients $[10,22]$. Addition of trastuzumab to anthracycline-based chemotherapy was associated with more frequent occurrence of heart failure (27\%) in comparison with addition of trastuzumab to chemotherapy without anthracyclines [10, 23]. Other recognized risk factors of cardiotoxicity are: old age of patients [24], baseline lower LVEF rate $(55-60 \%)$ [20], obesity, hypertension, diabetes and previous radiotherapy to the left side of the chest [25]. Baseline LVEF > 55\%, longer interval between chemotherapy containing anthracyclines, radiotherapy and immunotherapy and more often performed heart evaluation in UKG (echocardiography) are associated with the decrease of treatment cardiotoxicity [26].

Although cardiac adverse side effects (shortness of breath, significant impairment of exercise tolerance, stenocardial disorders) and the decrease of LVEF > 15\% were observed only in patients with negative receptor status, the performed analysis did not demonstrate an association between steroid receptor status and predisposition to cardiac side effects of trastuzumab treatment. Patients with negative estrogen receptor status are at 6.5 times higher risk of treatment discontinuation because of cardiac side effects. According to the literature, the reduced level of ER $\alpha$ affects the development of coronary heart disease in women. In coronary arteries of healthy women high expression of ER $\alpha$ occurs. However, the level of ER $\alpha$ decreases in ischemic heart disease. It is associated with higher methylation of genes encoding ER in atherosclerotically altered vessels in comparison with normal blood vessels [27]. In data from animal models the lack of ER $\beta$ receptor causes hypertension development, left ventricular hypertrophy and abnormal vascular function. Both types of receptors, ER $\alpha$ and $E R \beta$, are localized in vascular endothelial cells, vascular smooth muscle cells and cardiomyocytes. Nitric oxide (NO) released in a non-genomic mechanism induces relaxation of vascular smooth muscle. Data from animal models suggest participation of ER $\alpha$ receptors in contractility of cardiomyocytes, hypertrophy reduction and cardioprotection [28].

In evaluation of treatment response, $C R+P R$ were observed more often in patients with positive steroid receptor status. No difference in local recurrence and disease dissemination was detected. Other studies have shown that pathological complete remission $(p C R)$ rates were significantly higher in triple negative breast cancer patients irrespective of their age [29]. According to the data, HER2 overexpression is associated with worse prognosis and with more aggressive outcome, especially for estrogen-positive breast cancer. Estrogens can additionally stimulate proliferation of cancer cells through HER2 stimulation [16]. The nuclear receptor $E R \alpha$ interacts with the promoter region of the gene encoding HER2 and then inhibits transcription of HER2 mRNA. Simultaneously, activated ER $\alpha$, located near the cell membrane, stimulates phosphorylation and activation of membrane tyrosine kinase receptors such as EGFR family receptors including HER2. Next the proliferating signal is passed from the HER2 receptor into the cell, despite the absence of a specific ligand. This signal is triggered indirectly by estrogen stimulation [30]. The use of hormone therapy in patients with a positive steroid receptor status improves prognosis in this group of patients.

In conclusion, in the analyzed group of patients, risk factors for cardiac toxicity included: older age, previous radiotherapy to the left side of the chest and previous anthracycline-based chemotherapy. There was no influence of steroid receptor status on the cardiac side effects. Breast cancer type involving Erb-B2 overexpression was associated with predisposition to cardiotoxicity. The results require confirmation in a larger group of patients.

\section{Conflict of interest}

The authors declare no conflict of interest.

\section{References}

1. Slamon DJ, Clark GM, Wong SG, Levin WJ, Ullrich A, McGuire WL. Human breast cancer: correlation of relapse and survival with amplification of the HER-2/neu oncogene. Science 1987; 235: 177-82.

2. Masri S, Phung S, Wang X, et al. Genome-wide analysis of aromatase inhibitor-resistant, and long-term estrogen-deprived cells reveals a role for estrogen receptor. Cancer Res 2008; 68: 4910-8.

3. Ellis MJ, Tao Y, Young O, et al. Estrogen independent proliferation is present in estrogen-receptor HER-positive primary breast cancer after neoadjuvant latrozole. J Clin Oncol 2006; 24: 3019-25.

4. Rakha EA, El-Sayed ME, Green AR, et al. Biologic and clinical characteristics of breast cancer with single hormone receptor-positive phenotype. J Clin Oncol 2007; 25: 4772-8.

5. Kastner P, Krust A, Turcotte B, et al. Two distinct estrogen-regulated promoters generate transcripts encoding the two functionally different human progesterone receptors forms A and B. EMBOJ 1990; 9: 1603-14.

6. Cleator S, Heller W, Coombs RC. Triple-negative breast cancer: therapeutic options. Lancet Oncol 2007; 8: 23544.

7. Deroo BJ, Korach KB. Estrogen receptors and human disease. J Clin Invest 2006; 116: 561-70.

8. Kalita K, Lewandowski S, Skrzypczak M, et al. Estrogen receptors. In: Receptors and signal transduction mechanisms [Polish]. Nowak J, Zawilska JB (ed.). PW, Warsaw 2004. 
9. Piekarski J. Estrogen and progesterone receptors in breast cancer - current state of knowledge [Polish] Contemp Oncol 2005; 9: 371-9.

10. Yeh ET, Tong AT, Lenihan DJ, et al. Cardiovascular complications of cancer therapy: diagnosis, pathogenesis, and management. Circulation 2004; 109: 3122-31.

11. Seidman A, Hudis C, Pierri MK, et al. Cardiac disfunction in the trastuzumab clinical trials experience. J Clin Oncol 2002; 20: 1215-21.

12. Shaerman AM, Cupples LA, Demissie S, et al. Association between estrogen receptor alpha gene variation and cardiovascular disease. JAMA 2003; 290 2263-70.

13. Peter I, Shearman AM, Vasan RS, et al. Association of estrogen receptor beta gene polymorphisms with left ventricular mass and wall thickness in women. Am J Hypertens 2005; 18: 1388-95.

14. Goldhirsch A, Wood WC, Coates AS, et al. Strategies for subtypes: dealing with the diversity of breast cancer: highlights of the St. Gallen International Expert Consensus on the primary therapy of early breast cancer 2011 [Polish]. Ann Oncol 2011; 22: 1736-47.

15. Piotrowski G, Gawor R, Stasiak A, Gawor Z, Podemski P, Banach M. Cardiac complications associated with trastuzumab in the setting of adjuvant chemotherapy for breast cancer overexpressing human epidermal growth factor receptor type 2 a prospective study. Arch Med Sci 2012; 6: 227-35.

16. Stierer M, Rosen $\mathrm{H}$, Weber R, et al. Immunohistochemical and biochemical measurement of estrogen and progesterone receptors in primary breast cancer. Correlation of histopathology and prognostic factors. Ann Surg 1993; 218: 13-21.

17. Dębska S, Potemski P. Hormonal treatment of breast cancer patients with HER2 overexpression [Polish]. Onkol Prakt Klin 2010; 6: 301-10.

18. Kozakiewicz K, Wycisk A. Hormone replacement therapy and estrogen receptor modulators in the prevention of cardiovascular disease [Polish]. Wiad Lek 2006; 5-6: 377-82.

19. Grady D, Rubin SM, Petitti DB, et al. Hormone therapy to prevent disease and prolong life in postmenopausal women. Ann Intern Med 1992; 117: 1016-37.

20. Piccart-Gebhart MJ, Procter M, Leyland-Jones B, et al. Trastuzumab after adjuvant chemotherapy in HER2-positive breast cancer. N Engl J Med 2005; 353: 1659-72.

21. Romond EH, Perez EA, Brvant J, et al. Trastuzumab plus adjuvant chemotherapy for operable HER2-positive breast cancer. N Engl J Med 2005; 353: 1673-84.

22. Seidman A, Hudis C, Pierri MK, et al. Cardiac disfunction in the trastuzumab clinical trials experience. J Clin Oncol 2002; 20: 1215-21.

23. Slamon D, Eiermann W, Robert N, et al. Phase III randomized trial comparing doxorubicin and cyclophosphamide followed by docetaxel (ACT) with doxorubicin and cyclophosphamide followed by docetaxel and trastuzumab (AT) with docetaxel, carboplatin, and trastuzumab (THC) in HER2 positive early breast cancer patients: BCIRG 006 study. Breast Cancer Res Treat 2005; 94 (Supl. 1): S5.

24. Keefe DL. Trastuzumab-associated cardiotoxicity. Cancer 2002; 95: 1592-600.

25. Perez EA, Rodeheffer R. Clinical cardiac tolerability of trastuzumab. J Clin Oncol 2004; 22: 322-9.

26. Suter TM, Procter M, van Veldhuisen DJ, et al. Trastuzumab-associated cardiac adverse effects in the herceptin adjuvant trial. J Clin Oncol 2007; 25: 3859-65.
27. Wang M, Crisostomo P, Wairiuko GM, Meldrum DR. Estrogen receptor-alpha mediates acute myocardial protection in females. Am J Physiol Heart Physiol 2009; 290: 2204-9.

28. Jager T, Pelzer T, Müller-Botz S, Imam A, Muck J, Neyses L. Mechanisms of estrogen receptor action in the myocardium. J Biol Chem 2001; 276: 27873-80.

29. Kołacińska A, Chałubińska J, Błasińska-Morawiec M, et al. Pathological complete response in younger and older breast cancer patients. Arch Med Sci 2012; 8: 310-5.

30. Janik-Papis K, Błasik J. Breast cancer markers. Part II: Progression and new candidates [Polish]. Nowotwory J Oncol 2010; 3: 236-47. 